OPEN

SUBJECT AREAS:

NEUROSCIENCE

MOTIVATION

REWARD

Received

17 September 2014

Accepted

14 October 2014

Published

3 November 2014

Correspondence and requests for materials should be addressed to

D.M.D. (ddietz@

buffalo.edu)

* These authors contributed equally to this work.

\section{Prolonged withdrawal following cocaine self-administration increases resistance to punishment in a cocaine binge}

\author{
Amy M. Gancarz-Kausch*, Danielle N. Adank* \& David M. Dietz
}

Department of Pharmacology \& Toxicology; Research Institute on Addictions, Program of Neuroscience, University at Buffalo, Buffalo New York 14214, USA.

Drug addiction is characterized by compulsive drug-taking behaviors and a high propensity to relapse following drug cessation. Drug craving and seeking can increase during a period of abstinence, but this phenomenon is not observed in drug-induced reinstatement models. To investigate the effect of withdrawal on cocaine relapse, rats were exposed to extended-access cocaine self-administration and subjected to either 1 or $30 \mathrm{~d}$ of withdrawal. When tested during $12 \mathrm{~h}$ unlimited access to cocaine (binge), the duration of the withdrawal did not influence cocaine intake. However, using a histamine punishment procedure that greatly suppresses drug-taking behavior, we demonstrate that longer periods of abstinence from cocaine induce a greater persistence in responding for drug in the face of negative consequences.

ubstance abuse is a chronic disorder described as: (i) a progression from recreational drug use to compulsive drug-taking behavior; (ii) continued drug use in the face of negative consequences; (iii) difficulty in limiting drug intake; and (iv) a high propensity to relapse following drug cessation ${ }^{1-4}$. Relapse is often highest during withdrawal from prolonged access to psychomotor stimulants ${ }^{5}$. For example, cocaine addiction is characterized by high rates of relapse ${ }^{6}$ and binge episodes following abstinence ${ }^{7,8}$. A reported $90 \%$ of cocaine addicts relapse after prolonged abstinence ${ }^{9,10}$. Moreover, addicts continue to use cocaine despite knowledge of having a persistent physical or psychological problem and aversive consequences associated with continued use ${ }^{11}$, which is a diagnostic criterion for substance dependence disorder according to Fifth Edition of the Diagnostic and Statistical Manual of Mental Disorders ${ }^{12}$. However, despite intense efforts to understand the behavioral and neurobiological mechanisms underling drug addiction, there are currently no approved treatments for cocaine addiction to reduce incidences of relapse.

In order to identify novel pharmacologic and behavioral interventions to diminish the susceptibility to relapse, which can be triggered by associated cues $^{13}$, researchers have studied models of reinstatement in laboratory animals $^{14-16}$. In these studies, animals are trained to self-administer drug in the presence of distinct cues (e.g., tone, light), after which extinction is induced by repeated sessions in which responding no longer results in presentation of drug infusions or cue presentations. Responding is "reinstated" after a priming drug injection or presentation of a cue previously paired with drug delivery, which is considered a model of drug-seeking/ craving ${ }^{14,16-22}$.

Historically, cocaine cessation was considered somewhat benign because of relatively few overt physical symptoms ${ }^{23-25}$. However, cocaine cessation leads to a wide range of psychological and physical symptoms including dysphoria, depression, anxiety, insomnia, changes in appetite, psychomotor retardation, and drug craving $^{26-32}$. In the human condition, drug abstinence is often a non-voluntary forced abstinence (e.g., incarceration, in-patient rehabilitation, etc.). In contrast, drug cessation in the reinstatement model is via experimenterimposed extinction procedures that have a learning component ${ }^{33,34}$. Thus, it has been argued that animal models of forced abstinence (e.g., withdrawal) are a better model of the human condition ${ }^{35}$. In preclinical rodent models, cue-induced craving for cocaine increases over periods of forced abstinence/withdrawal as measured by extinction/reinstatement procedures ${ }^{18,36-41}$.

The aim of the present study was to determine whether prolonged periods of forced abstinence/cocaine withdrawal increase drug-seeking and drug-taking behaviors. To answer this, rats were given extended access to cocaine self-administration (SA), which models the "loss of control" observed in humans. Following 1 or $30 \mathrm{~d}$ of forced abstinence, animals were then given unlimited access to cocaine in an SA "binge" paradigm ${ }^{42-47}$, which elicits a pattern of SA comparable to that of a "compulsive" drug user"44,45,48-51. Furthermore, the effect of 
withdrawal on punished cocaine SA was investigated, during which infusions of cocaine were mixed with histamine. Histamine administration models the consequence of protracted cocaine use in humans that is characterized by an aversive, delocalized itching sensation throughout the body ${ }^{52}$. In the laboratory, intravenously delivered histamine effectively reduces responding for a natural reinforcer ${ }^{53}$ and drug self-administration in rats ${ }^{54}$ and non-human primates $^{55,56}$, presumably by mimicking or enhancing this aversive sensation.

\section{Results}

Cocaine SA. A two-factor repeated measures ANOVA with drug (cocaine, saline) and withdrawal period (1 WD, $30 \mathrm{WD})$ as between-subject factors and time (day of testing) as within-subject factor revealed a main effect of $\operatorname{drug}(\mathrm{F}[1,72]=123.771 ; P<0.001)$, and an interaction between time and drug $(\mathrm{F}[9,648]=1.919 ; P<$ 0.05 ) (Fig. 1a), indicating that animals assigned to cocaine groups self-administer significantly more infusions than rats assigned to saline groups, and no significant differences in drug intake occurred in animals assigned to 1 or $30 \mathrm{WD}$. Animals were further counterbalanced and assigned to cue-induced reinstatement, binge test, or punished SA (Fig. 1b). In order to further control for drug histories, the average number of drug infusions was analyzed over the last $4 \mathrm{~d}$ of extended access across the cocaine groups: cue-induced reinstatement, $102.9 \pm 9.3$ and $111.5 \pm 5.2$; cocaine binge test, 110.1 \pm 110.4 and $110.4 \pm 10.3$; and punished cocaine $S A, 100.6 \pm 5.2$ and
$107.7 \pm 9.0$, for 1 and $30 \mathrm{WD}$, respectively. There were no significant differences in drug intake between 1 and $30 \mathrm{WD}$.

Incubation of cocaine seeking. In order to determine changes in drug-seeking following periods of withdrawal, the number of active responses during cue-induced reinstatement was analyzed. A twofactor ANOVA revealed main effects of $\operatorname{drug}(\mathrm{F}[1,36]=38.707 ; P<$ $0.05)$ and withdrawal period $(\mathrm{F}[1,36]=7.988 ; P<0.05)$, and an interaction between them $(\mathrm{F}[1,36]=12.655 ; P<0.05)$. After one day of withdrawal, animals with a history of cocaine had significantly more active responses than animals with a history of saline $(\mathrm{F}[1,18]$ $=10.628 ; P<0.05)$. Similarly, animals with a history of cocaine had significantly more active responses than those with a history of saline after $30 \mathrm{~d}$ of withdrawal $(\mathrm{F}[1,16]=25.387 ; P<0.05)$ (Fig. 2). In animals with a history of cocaine, a follow-up one-factor ANOVA revealed a significant difference between withdrawal groups ( $\mathrm{F}[1$, $20]=13.772 ; P<0.01$ ), indicating that animals with $30 \mathrm{~d}$ of withdrawal had a greater number of active responses compared to their 1 WD counterparts. Active responses did not differ between 1 and $30 \mathrm{WD}$ animals that received saline.

Relapse to cocaine re-exposure (binge). A two-factor ANOVA revealed a significant main effect of drug on the number of infusions self-administered during a 12-h-binge $(\mathrm{F}[1,40]=$ 92.011; $P<0.001)$. In animals with a history of cocaine, there was no significant difference between the withdrawal groups in the number of infusions (Fig. 3a) or the cumulative dose of cocaine

a

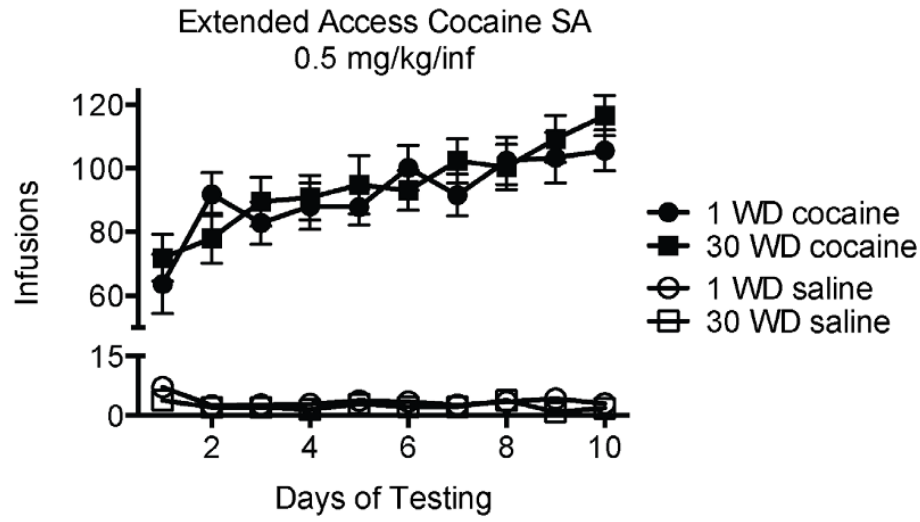

b

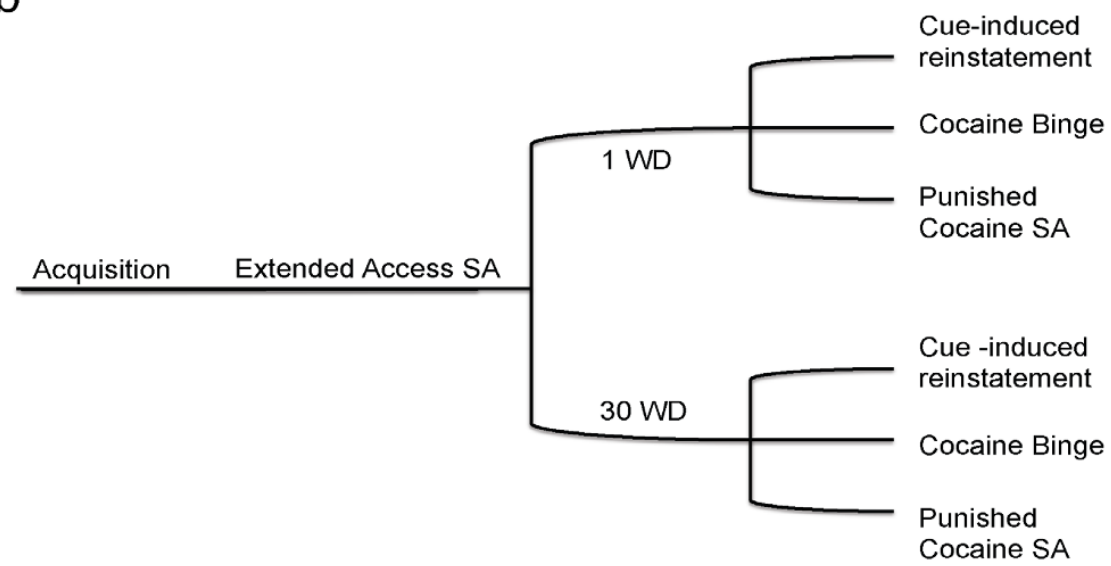

Figure 1 Extended access self-administration (SA). (a) The number of infusions of cocaine ( $0.5 \mathrm{mg} / \mathrm{kg} / \mathrm{inf})$ or saline self-administered per day across the $10 \mathrm{~d}$ testing protocol in animals subsequently assigned to $1 \mathrm{~d}(1 \mathrm{WD}$; cocaine $n=33$, saline $n=16)$ or $30 \mathrm{~d}$ ( $30 \mathrm{WD}$; cocaine $n=32$, saline $n=14)$ of withdrawal. (b) Timeline of behavioral testing for (i) cue-induced reinstatement, (ii) cocaine binge test, or (iii) punished cocaine SA. 


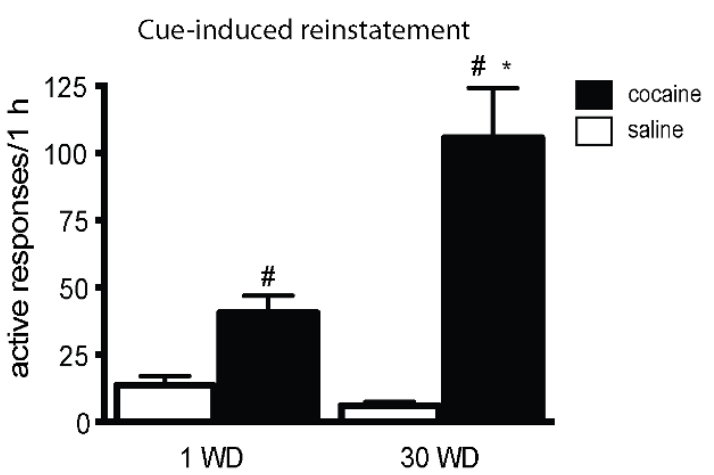

Figure $2 \mid$ Cue-induced reinstatement. The number of responses to the active alternative following $1 \mathrm{~d}(1 \mathrm{WD}$; cocaine $n=12$, saline $n=8)$ or $30 \mathrm{~d}$ (30 WD; cocaine $n=9$, saline $n=8$ ) of withdrawal. Data are expressed as the average \pm standard error; ${ }^{*} P<0.05$ vs. $1 \mathrm{WD},{ }^{*} P<0.05 v s$. saline.

received (Fig. 3b). In addition, no significant effect of withdrawal period was observed following a history of saline.

A mixed, two-factor, repeated measures ANOVA was performed, with drug and withdrawal as between-subject factors and time as the within-subject factor, to examine the pattern of drug intake across the 12-h-binge, revealing main effects of time $(\mathrm{F}[11,407]=2.269 ; P$ $<0.05)$ and drug $(\mathrm{F}[1,37]=91.891 ; P<0.001)$. A follow-up analysis revealed only a main effect of time for animals receiving cocaine $(\mathrm{F}[11,275]=2.850 ; P<0.001)$, indicating that the pattern of SA during the binge did not differ between the 1 and $30 \mathrm{WD}$ groups.

Cumulative dose of cocaine self-administered was analyzed using a two-factor, repeated measures ANOVA, which showed a main effect of time $(\mathrm{F}[11,275]=169.189 ; P<0.01)$, and a time $\times$ withdrawal period interaction $(\mathrm{F}[11,275]=1.871 ; P<0.05)$. A follow-up post hoc Bonferroni's multiple comparison test revealed no significant differences between the 1 and $30 \mathrm{WD}$ group at any time during the binge, with similar patterns of self-administered infusions (Fig. 3c) and cumulative dose of cocaine (Fig. 3d).

In order to determine if the amount of drug self-administered during a binge episode was associated with previous drug intake, correlation coefficients between the average numbers of cocaine infusions self-administered during days 8-10 of extended access and during the binge were calculated. There was a significant positive correlation between the number of infusions self-administered during the binge and during extended access in the $1 \mathrm{WD}$ group $(\mathrm{r}=$ $0.72 ; P<0.05)$ (Fig. 3e). However, this association was not observed after $30 \mathrm{~d}$ of withdrawal ( $\mathrm{r}=0.479$ ) (Fig. $3 \mathrm{f}$ ).

Finally, in order to determine changes in drug-seeking persistence following periods of withdrawal, active responses during the timeout periods of the cocaine binge were analyzed by a two-factor ANOVA, revealing a significant main effect of drug on the number of active responses $(\mathrm{F}[1,40]=4.142 ; P<0.05)$. A follow-up onefactor ANOVA revealed that with a history of cocaine, animals in the $30 \mathrm{WD}$ group had significantly more active responses during the time-out period than the $1 \mathrm{WD}$ group $(\mathrm{F}[1,26]=4.502 ; P<$ 0.05 ) (Fig. 3g). Withdrawal time did not influence time-out active responses in animals with a history of saline. There were no significant changes in general arousal following periods of withdrawal, as assessed by the number of inactive responses (data not shown).

Punished cocaine binge. A two-factor ANOVA revealed main effects of punisher (histamine vs. no histamine) $(\mathrm{F}[1,40]=$ 12.826; $P<0.01)$ and withdrawal period $(\mathrm{F}[1,40]=6.141 ; P<$ $0.01)$. Follow-up one-way ANOVAs revealed that animals selfadministered significantly fewer infusions of punished cocaine than unpunished cocaine both after $1 \mathrm{WD}(\mathrm{F}[1,20]=4.502 ; P<$
$0.05)$ and $30 \mathrm{WD}(\mathrm{F}[1,22]=5.907 ; P<0.05)$, indicating that histamine was an effective punisher (data not shown).

In order to determine if withdrawal alters drug-taking in the presence of negative consequences, the number of infusions and cumulative dose of cocaine self-administered during the punished cocaine binge were analyzed. Animals in the $30 \mathrm{WD}$ HIST group self-administered significantly more infusions of the cocaine/histamine cocktail compared to animals in the 1 WD HIST group $(\mathrm{F}[1,16]=4.732$; $P<0.05$ ) (Fig. 4a). Animals in the 30 WD HIST group also selfadministered a significantly greater cumulative dose of cocaine compared to $1 \mathrm{WD}$ HIST counterparts $(\mathrm{F}[1,16]=4.732 ; P<0.05)$ (Fig. 4b). No differences were observed in active responses during the time-out period (Fig. $4 \mathrm{~g}$ ) or in the total number of inactive responses (data not shown).

A mixed, two-factor repeated measures ANOVA revealed main effects of time $(\mathrm{F}[11,165]=4.290 ; P<0.05)$ and withdrawal period $(\mathrm{F}[1,15]=4.747 ; P<0.001)$, and an interaction between the two factors $(\mathrm{F}[11,165)=2.004 ; P<0.05)$ on the number of infusions per hour. A follow-up post hoc Bonferroni's multiple comparison test revealed that rats in the $30 \mathrm{WD}$ HIST group self-administered significantly more infusions at hours 5,7 , and 9 compared to rats in the 1 WD HIST group $(P s<0.05)$ (Fig. $4 \mathrm{c})$. There was also a main effect of time $(\mathrm{F}[11,165]=33.622 ; P<0.01)$ and a time $\times$ withdrawal period interaction $(\mathrm{F}[11,165]=5.065 ; P<0.01)$ for cumulative dose self-administered. The post hoc analysis revealed that animals in the 30 WD HIST group had a significantly higher cumulative dose of cocaine than those in the 1 WD HIST at hours 7-12 (Fig. 4d).

Correlational analyses revealed a significant positive association between the average number of infusions during days 8-10 of extended access and the number of punished cocaine infusions after $1 \mathrm{WD}(\mathrm{r}=0.683 ; P<0.05)$, but not after $30 \mathrm{WD}(\mathrm{r}=0.556)$ (Fig. 4e,f).

\section{Discussion}

Longer periods of drug abstinence result in an incubation of cueinduced reinstatement and drug-seeking consistent with findings reported by Grimm et al. ${ }^{37}$. However, there is no such increase in drug-taking when cocaine was readily available following longer withdrawal periods. This discrepancy may be due to the fact that these tests measure two different types of drug-related behaviors. Cue-induced reinstatement measures drug-seeking, as responses do not result in drug procurement, whereas actual drug-taking is measured in a cocaine binge.

Intriguingly, animals that underwent $30 \mathrm{~d}$ of withdrawal made more active responses during the time-out period when drug was unavailable, which is consistent with the incubation effect observed in cue-induced reinstatement. This is a model of compulsive responding ${ }^{57-59}$, which is considered an addiction-like criterion in the rat, and is analogous to the difficulty in stopping drug use or limiting drug intake in humans. These data suggest that although withdrawal does not influence binge intake, it may increase compulsive drug-seeking behaviors during periods of drug unavailability. The use of more sophisticated animal models that simultaneously examine drug-taking and drug-seeking components of relapse using a between-session progressive ratio cocaine SA procedure ${ }^{60}$ may be able to more carefully dissect their individual roles following periods of drug abstinence.

The fact that drug intake remained unchanged after $30 \mathrm{~d}$ of withdrawal demonstrates the stability of the learned associations that occur during drug SA, compared to other forms of operant learning which may decay in performance as early as $72 \mathrm{~h}$ after the last training session ${ }^{61}$. This stability is remarkable, given that extended access to cocaine SA produces significant cognitive deficits and impairments in working memory that can persist for at least one month ${ }^{62-65}$. Such cognitive impairments have also been observed in humans after two weeks of abstinence ${ }^{66}$. 

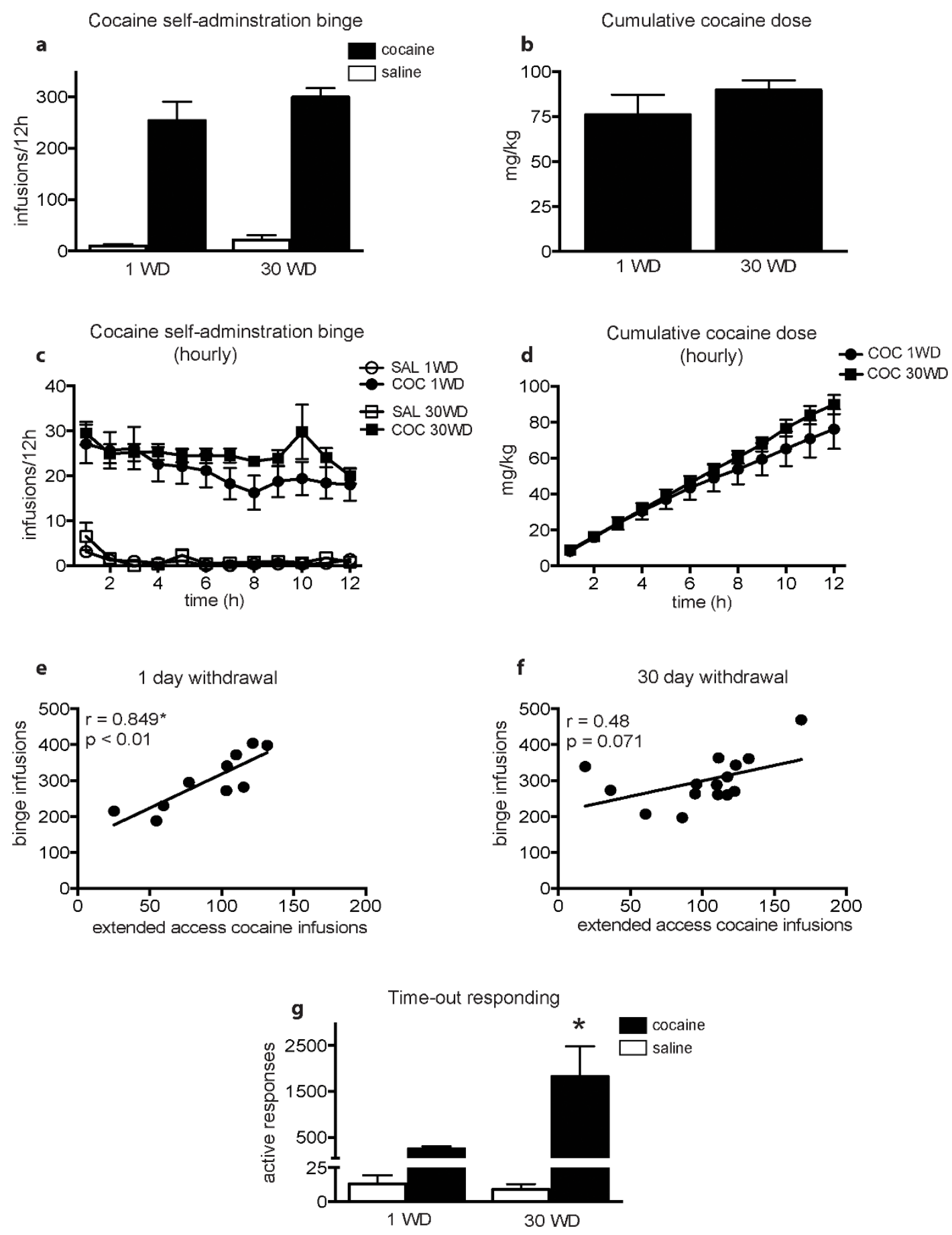

Figure 3 Cocaine self-administration binge. (a) Average number of infusions, (b) cumulative dose, (c) average number of hourly infusions, (d) cumulative hourly dose during the 12-h-binge (e) correlation of prior self-administration and binge cocaine performance after $1 \mathrm{~d}$ and (f) $30 \mathrm{~d}$ of withdrawal, and (g) number of non-reinforced active responses during the 12-h-binge following $1 \mathrm{~d}$ ( $1 \mathrm{WD}$; cocaine $n=12$, saline $n=8$ ) or $30 \mathrm{~d}$ ( $30 \mathrm{WD}$; cocaine $n=15, n=6$ ) of withdrawal. Black bars represent animals self-administering cocaine, white bars represent animals self-administering saline. Data are expressed as the average \pm standard error; ${ }^{*} P<0.05$ vs. $1 \mathrm{WD}$.

One of the hallmarks of cocaine addiction is the regular, continued use of drug despite negative consequences (e.g., health complications, risk of incarceration, etc.). The results of this study demonstrate that a prolonged withdrawal increases the amount of punished cocaine that is self-administered. These findings are consistent with previous reports showing that motivation, as measured by progressive ratio, was increased following withdrawal, though, this may be dependent on withdrawal and drug histories ${ }^{67}$. Importantly, these data suggest that negative and aversive consequences are less effective for preventing drug-taking following long periods of abstinence. However, this may be dependent on the timing in which the punishment is administered, as Barnea-Ygael et al. found that increasing withdrawal periods attenuated drug-seeking relapse behaviors following exposure to a conflict SA model in which punishment was administered prior to withdrawal ${ }^{68}$.

Interestingly, cocaine intake was only positively associated with binge intake following a short withdrawal period, suggesting that drug history is not effective in predicting propensity of relapse 
a Punished cocaine self-adminstration binge

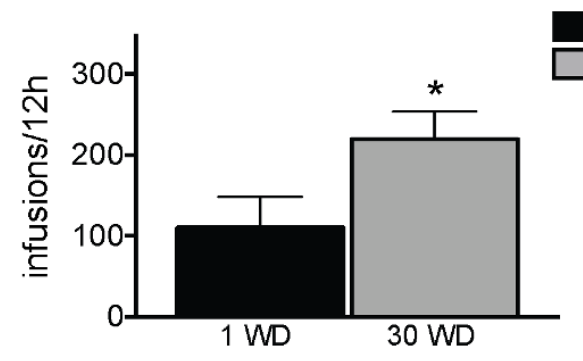

c Punished cocaine self-adminstration binge (hourly)

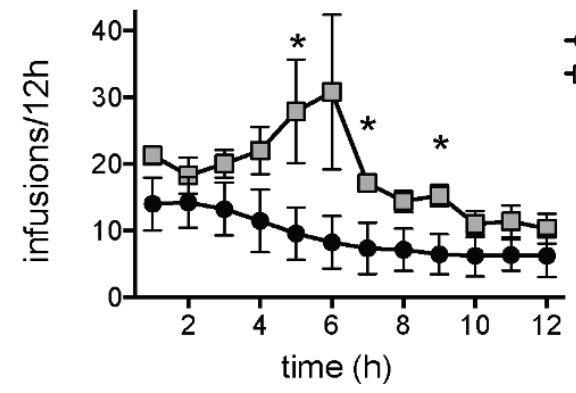

e

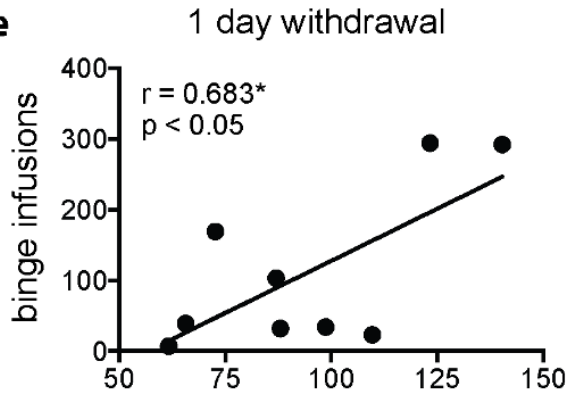

extended access cocaine infusions b Cumulative punished cocaine dose

1 WD HIST

30 WD HIST

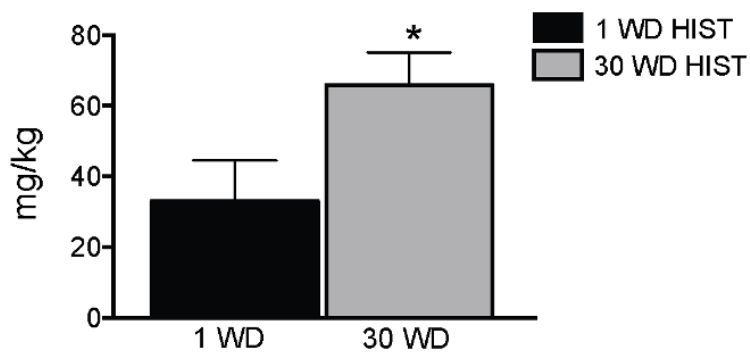

d Cumulative punished cocaine dose

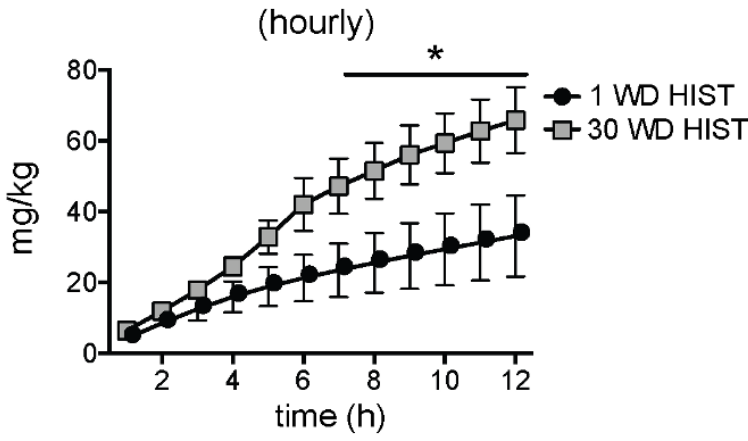

f

30 day withdrawal

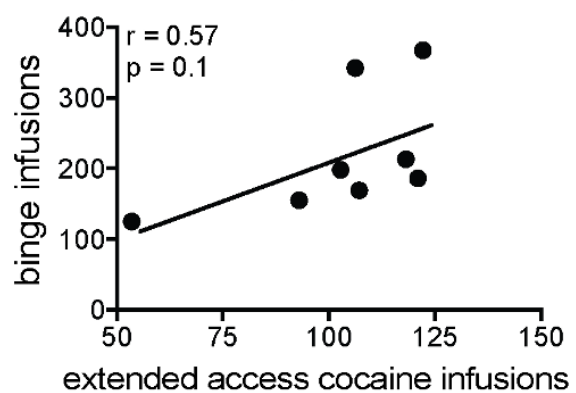

g Time-out responding

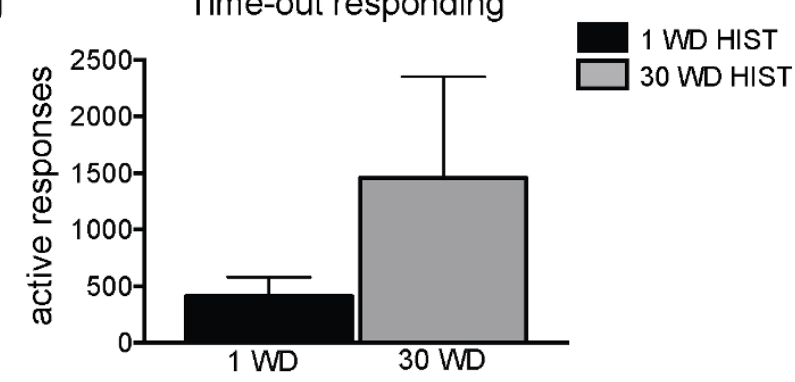

Figure 4 Self-administration of punished cocaine. (a) Average number of punished infusions, (b) cumulative punished cocaine dose, (c) average number of hourly infusions, (d) cumulative hourly dose during the 12-h-binge (e) correlation of prior self-administration and punished cocaine performance after $1 \mathrm{~d}$ and ( $\mathrm{f}$ ) $30 \mathrm{~d}$ of withdrawal, and (g) number of non-reinforced active responses during the punished cocaine binge following $1 \mathrm{~d}$ ( 1 WD HIST, $n=9$ ) or $30 \mathrm{~d}$ (30 WD HIST, $n=8$ ) of withdrawal. Black bars represent animals self-administering cocaine, grey bars represent animals selfadministering cocaine/histamine cocktail. Data are expressed as the \pm standard error; ${ }^{*} P<0.05$ vs. 1 WD HIST.

following longer abstinence periods. Weiss et al. also reported that the severity of cocaine dependence in patients diagnosed with cocaine addiction was a poor predictor of relapse in a three-month follow-up after hospitalization ${ }^{48}$.
The increase in cocaine seeking that was observed after prolonged withdrawal combined with access to cocaine has grave implications for the human condition. These data suggest that despite averse consequences, the potential to relapse is unaffected by withdrawal. 
Indeed, lifelong behavioral and neuronal plasticity occurs following drug exposure ${ }^{69-72}$, which is thought to drive the cycle of abstinence and relapse that is a hallmark of drug addiction.

Few studies have measured the time-course of drug craving in a naturalistic setting, and clinical studies have contradictory reports across periods of withdrawal. Some studies report that craving for cocaine time-dependently increases over periods of forced abstinence/withdrawal ${ }^{7,26}$, whereas others report decreases in craving over $28 \mathrm{~d}^{73}$. Furthermore, wide ranging individual differences in drug craving across time have also been reported ${ }^{74}$. A universal limitation of these human studies is that drug craving is measured in an environment different from the environment where drugtaking occurs, emphasizing the importance of the use of realistic animal models.

In an effort to translate animal models of drug-seeking, drug-taking and relapse into therapeutic interventions, in future studies it will be critical that we use such models to elucidate a full and thorough understanding of the neurobiology that mediates these behaviors. For example, there are several reports that investigate neuronal adaptions as key mediators of the addicted state and relapse, including alterations of glutamatergic synapse function and composition ${ }^{75-79}$, neurotrophic factors ${ }^{36}$ and structural plasticity ${ }^{80}$. Furthermore, it is essential to profile the transcriptional and epigenetic alterations that may mediate our behavioral findings. For example, withdrawal from cocaine has also been linked to gene priming or desensitization resulting from functional changes in the chromatin state around individual genes ${ }^{81,82}$. These changes in the transcriptional and epigenetic landscape following chronic cocaine provide a plausible mechanism by which relapse occurs despite long periods of abstinence ${ }^{83}$. Finally, although the data presented here are restricted to cocaine, it is critical to understand whether the stability of drug consumption and resistance to negative consequences occur following exposure to other drugs of abuse, such as opiates, nicotine, and alcohol.

Our results demonstrate that withdrawal from cocaine alters aspects of future susceptibility to relapse in a cocaine binge. Although binge drug-taking remained stable, there is incubation of compulsive drug-seeking behaviors following prolonged periods of drug withdrawal. Furthermore, prolonged withdrawal decreases the effectiveness of a punisher in a cocaine binge. Broadly, these data suggest more clinical intervention is necessary than simple forced abstinence from the drug to decrease future drug relapse. These findings highlight the need for a deeper and more complete understanding of time-dependent behavioral and neuronal adaptations to provide effective clinical intervention to prevent future drug relapse. These punished and unpunished binge paradigms show face validity to the human condition, as resumption of drug-taking behavior is recorded, unlike traditional reinstatement paradigms. Such binge paradigms provide unique results in measuring true 'relapse' following periods of withdrawal. Future studies are needed to further investigate the drug-seeking/drug-taking differences observed in relapse following increasing periods of withdrawal. Targeting and understanding relapse in human addicts will be essential for progressive interventions for cocaine addiction.

\section{Methods}

Animals. Male Sprague-Dawley rats (300 g; Harlan Laboratories, Indianapolis, IN, USA) were allowed to acclimate for three days upon arrival to the colony room and housed on a $12 \mathrm{~h}$ light-dark cycle with ad libitum access to food and water. Rats were singly housed following surgery and for the duration of the experiment in order to protect the catheter/harness assembly. Testing took place seven days/wk during the rats' dark phase of the light-dark cycle. This study and all experimental protocols were approved and the methods were carried out in accordance within the guidelines of the Institutional Animal Care and Use Committee of the State University of New York at Buffalo.

Self-administration test chambers. The experimental chambers have been described elsewhere ${ }^{84}$. Briefly, 16 standard test chambers (MED Associates, Inc., St. Albans, VT, USA) were equipped with two snout-poke holes that were monitored with infrared detectors. Two stimulus lights were mounted above the snout-poke holes, and a houselight was mounted in the middle of the back wall of the test chamber. All test chambers were housed in sound-attenuating chambers. Test chambers were computer controlled through a MED Associates interface with a temporal resolution of $0.01 \mathrm{~s}$.

Drugs. Solutions of (-)-cocaine hydrochloride (NIDA drug supply program) dissolved in sterile $0.9 \%$ saline were prepared on a weekly basis (acquisition, $4.5 \mathrm{mg}$ / $\mathrm{mL}$; extended access, $1.7 \mathrm{mg} / \mathrm{mL}$; cocaine binge, $1.0 \mathrm{mg} / \mathrm{mL}$ ). Pump durations were adjusted according to body weight on a daily basis in order to deliver the correct dose of drug (acquisition, $1.0 \mathrm{mg} / \mathrm{kg} / \mathrm{inf}$; extended access, $0.5 \mathrm{mg} / \mathrm{kg} / \mathrm{inf}$; cocaine binge, $0.3 \mathrm{mg} / \mathrm{kg} / \mathrm{inf})$. During the punished cocaine binge, a cocaine $(1.0 \mathrm{mg} / \mathrm{mL}) /$ histamine $(13.4 \mathrm{mg} / \mathrm{mL}$ ) cocktail was used (cocaine, $0.3 \mathrm{mg} / \mathrm{kg} / \mathrm{inf}$; histamine, $4.0 \mathrm{mg} / \mathrm{kg} / \mathrm{inf})$.

Jugular catheterization and patency test. Rats were implanted with chronic indwelling jugular catheters and allowed seven days to recover following surgery as previously described ${ }^{60,85}$. Catheters were flushed daily with $0.2 \mathrm{~mL}$ of a heparinized saline solution $(50 \mathrm{IU} / \mathrm{mL})$ with enrofloxacin $(4 \mathrm{mg} / \mathrm{mL})$ to preserve patency. Tests of patency occurred once per week during which the behavioral response to an infusion of ketamine hydrochloride $(0.5 \mathrm{mg} / \mathrm{kg}$ in $0.05 \mathrm{~mL}$ saline; iv) was observed. Loss of muscle tone and righting reflexes served as behavioral indicators of patency. Only rats with patent catheters were used in data analyses.

Acquisition of SA. One week after jugular catheter surgery, rats were trained to selfadminister cocaine or saline. Responses to the active snout-poke hole initially resulted in infusions followed by a $30 \mathrm{~s}$ time-out period using a fixed ratio (FR) 1 schedule of reinforcement, which was increased daily to an FR5 schedule. Following each session, catheters were flushed and rats were returned to the colony room. The criterion for acquisition of cocaine SA was an average of ten infusions per day during the last three days of the acquisition period.

Extended-access SA. Following SA acquisition, rats were exposed to ten days of extended access. During this time, rats were allowed 6-h-access to cocaine $(n=89)$ or saline $(n=30)$ according to an FR5 schedule of reinforcement. Following each session, catheters were flushed and rats were returned to the colony room. Only rats that reached criterion of acquisition and maintained catheter patency were used in successive phases of the experiment. Failure to achieve acquisition or respond for cocaine resulted in the removal of the animal from the remainder of the study.

Withdrawal. Following extended access SA, rats were counterbalanced according to SA performance and assigned to receive either 1 or $30 \mathrm{~d}$ of withdrawal (1 WD and 30 WD, respectively). During the withdrawal periods, rats were returned to the colony room, flushed once per day, and otherwise left undisturbed in their home cages. Following cocaine SA, rats were then assigned to groups that participated in cueinduced reinstatement, cocaine re-exposure (binge) or punished cocaine responding (histamine).

Cue-induced reinstatement. Following withdrawal, $1 \mathrm{WD}$ (cocaine, $n=12$; saline, $n$ $=8$ ) and $30 \mathrm{WD}$ (cocaine, $n=9$; saline, $n=8$ ) rats were first exposed to multiple within-session extinction sessions, during which the chambers were dark and responses were recorded but resulted in no programmed consequences ${ }^{37}$. Sessions were $1 \mathrm{~h}$ in duration, separated by $5 \mathrm{~min}$, and were continued until responding levels were equivalent to saline ( $8-10$ sessions). On the subsequent day, animals were returned to their test chamber and given a 1-h-test of cue-induced reinstatement during which active responses produced cues previously paired with drug delivery.

Binge test. Following the assigned withdrawal period, rats were tested during a single 12 -h-period during which responses to the active snout-poke hole resulted in infusions according to an FR5 schedule of reinforcement (1 WD: cocaine, $n=12$; saline, $n=8$; and $30 \mathrm{WD}$ : cocaine, $n=15$; saline, $n=6$ ).

Punished SA. Following withdrawal, rats were tested during a single 12-h-period during which responses to the active snout-poke hole resulted in infusions of cocaine mixed with histamine according to an FR5 schedule of reinforcement (1 WD HIST, $n$ $=9 ; 30$ WD HIST, $n=8$ ).

Data analysis. Primary dependent measures were: (i) number of infusions selfadministered during extended access; (ii) number of active responses emitted during a test of cue-induced reinstatement; (iii) number of infusions self-administered during cocaine binge; (iv) cumulative cocaine dose ( $\mathrm{mg} / \mathrm{kg}$ ); (v) number of active responses emitted during the time-out period of the binge; and (vi) number of inactive responses during the binge. Performance during the binge was analyzed using a two-factor within-subject Analysis of Variance (ANOVA) with the betweensession variable as drug group (cocaine, saline) and the within-subject variable as time. One-factor ANOVAs were used to identify sources of significant interactions.

To compare hourly responding during the binge, a three-factor mixed ANOVA was used with drug (saline, cocaine) and withdrawal period (1,30 WD) as betweensubject factors, and time (h) as a within-subject factor. Follow-up two-way betweensubject ANOVAs were performed on the hourly data with drug and withdrawal period as the two factors.

Pearson correlation coefficients were determined between the average number of infusions self-administered on days $8-10$ of extended access and during the cocaine 
binge. All data were analyzed using SPSS software, and are represented as the mean \pm standard error, with $P<0.05$ indicating significance.

1. Koob, G. F. The neurobiology of addiction: a neuroadaptational view relevant for diagnosis. Addiction 101 Suppl 1, 23-30 (2006).

2. Koob, G. F., Caine, S. B., Parsons, L., Markou, A. \& Weiss, F. Opponent process model and psychostimulant addiction. Pharmacol Biochem Behav 57, 513-521 (1997).

3. Koob, G. F. \& Le Moal, M. Drug abuse: hedonic homeostatic dysregulation. Science 278, 52-58 (1997).

4. Koob, G. F. \& Nestler, E. J. The neurobiology of drug addiction. J Neuropsychiatry Clin Neurosci 9, 482-497 (1997).

5. Jaffe, J. H. Current concepts of addiction. Res Publ Assoc Res Nerv Ment Dis 70, 1-21 (1992).

6. Mendelson, J. H. \& Mello, N. K. Management of cocaine abuse and dependence. N Engl J Med 334, 965-972 (1996).

7. Gawin, F. H. Cocaine addiction: psychology and neurophysiology. Science 251, 1580-1586 (1991)

8. Dackis, C. A. \& O’Brien, C. P. Cocaine dependence: a disease of the brain's reward centers. J Subst Abuse Treat 21, 111-117 (2001).

9. DeJong, W. Relapse prevention: an emerging technology for promoting long-term drug abstinence. Int J Addict 29, 681-705 (1994).

10. O'Brien, C. P. Treatment of alcoholism as a chronic disorder. Alcohol 11, 433-437 (1994).

11. Petry, N. M. \& Bickel, W. K. Polydrug abuse in heroin addicts: a behavioral economic analysis. Addiction 93, 321-335 (1998).

12. American Psychiatric Association. Diagnostic and statistical manual of mental disorders. (5th ed.), American Psychiatric Publishing, Arlington VA, 2013.

13. O'Brien, C. P. Anticraving medications for relapse prevention: a possible new class of psychoactive medications. Am J Psychiatry 162, 1423-1431 (2005).

14. Shaham, Y., Shalev, U., Lu, L., De Wit, H. \& Stewart, J. The reinstatement model of drug relapse: history, methodology and major findings. Psychopharmacology (Berl) 168, 3-20 (2003).

15. de Wit, H. \& Stewart, J. Drug reinstatement of heroin-reinforced responding in the rat. Psychopharmacology (Berl) 79, 29-31 (1983).

16. de Wit, H. \& Stewart, J. Reinstatement of cocaine-reinforced responding in the rat. Psychopharmacology (Berl) 75, 134-143 (1981).

17. Crombag, H. S. \& Shaham, Y. Renewal of drug seeking by contextual cues after prolonged extinction in rats. Behav Neurosci 116, 169-173 (2002).

18. Meil, W. M. \& See, R. E. Conditioned cued recovery of responding following prolonged withdrawal from self-administered cocaine in rats: an animal model of relapse. Behav Pharmacol 7, 754-763 (1996).

19. Spealman, R. D., Barrett-Larimore, R. L., Rowlett, J. K., Platt, D. M. \& Khroyan, T. V. Pharmacological and environmental determinants of relapse to cocaineseeking behavior. Pharmacol Biochem Behav 64, 327-336 (1999).

20. Weiss, F. et al. Control of cocaine-seeking behavior by drug-associated stimuli in rats: effects on recovery of extinguished operant-responding and extracellular dopamine levels in amygdala and nucleus accumbens. Proc Natl Acad Sci U S A 97, 4321-4326 (2000)

21. Kalivas, P. W. \& McFarland, K. Brain circuitry and the reinstatement of cocaineseeking behavior. Psychopharmacology (Berl) 168, 44-56 (2003).

22. Stretch, R. \& Gerber, G. J. Drug-induced reinstatement of amphetamine selfadministration behaviour in monkeys. Can J Psychol 27, 168-177 (1973).

23. S, F. Freud's Studies on Cocaine, 1884-1887. Journal of the American Psychoanalytic Association 1, 581-613 (1953).

24. Jaffe, J. H. Further experience with methadone in the treatment of narcotics users. Int J Addict 5, 375-389 (1970).

25. Jaffe, J. H. (Ch 16) The pharmacological basis of therapeutics [Goodman, L. S. \& Gillman, A. (Eds.), $4^{\text {th }}$ ed.] [276-313] Macmillan, New York, (1970).

26. Gawin, F. H. \& Kleber, H. D. Abstinence symptomatology and psychiatric diagnosis in cocaine abusers. Clinical observations. Arch Gen Psychiatry 43, 107-113 (1986).

27. Weddington, W. W. et al. Changes in mood, craving, and sleep during short-term abstinence reported by male cocaine addicts. A controlled, residential study. Arch Gen Psychiatry 47, 861-868 (1990).

28. Satel, S. L. \& Edell, W. S. Cocaine-induced paranoia and psychosis proneness. Am J Psychiatry 148, 1708-1711 (1991)

29. Satel, S. L. \& McDougle, C. J. Obsessions and compulsions associated with cocaine abuse. Am J Psychiatry 148, 947 (1991).

30. Satel, S. L. et al. Clinical phenomenology and neurobiology of cocaine abstinence: a prospective inpatient study. Am J Psychiatry 148, 1712-1716 (1991).

31. Miller, N. S., Summers, G. L. \& Gold, M. S. Cocaine dependence: alcohol and other drug dependence and withdrawal characteristics. J Addict Dis 12, 25-35 (1993).

32. Sofuoglu, M., Dudish-Poulsen, S., Poling, J., Mooney, M. \& Hatsukami, D. K. The effect of individual cocaine withdrawal symptoms on outcomes in cocaine users. Addict Behav 30, 1125-1134 (2005).

33. Epstein, D. H. \& Preston, K. L. The reinstatement model and relapse prevention: a clinical perspective. Psychopharmacology (Berl) 168, 31-41 (2003).

34. Katz, J. L. \& Higgins, S. T. The validity of the reinstatement model of craving and relapse to drug use. Psychopharmacology (Berl) 168, 21-30 (2003).
35. Reichel, C. M. \& Bevins, R. A. Forced abstinence model of relapse to study pharmacological treatments of substance use disorder. Curr Drug Abuse Rev 2, 184-194 (2009)

36. Grimm, J. W. et al. Time-dependent increases in brain-derived neurotrophic factor protein levels within the mesolimbic dopamine system after withdrawal from cocaine: implications for incubation of cocaine craving. J Neurosci $\mathbf{2 3}$ 742-747 (2003).

37. Grimm, J. W., Hope, B. T., Wise, R. A. \& Shaham, Y. Neuroadaptation. Incubation of cocaine craving after withdrawal. Nature 412, 141-142 (2001).

38. Lu, L., Grimm, J. W., Hope, B. T. \& Shaham, Y. Incubation of cocaine craving after withdrawal: a review of preclinical data. Neuropharmacology 47 Suppl 1, 214-226 (2004).

39. Lu, L., Grimm, J. W., Dempsey, J. \& Shaham, Y. Cocaine seeking over extended withdrawal periods in rats: different time courses of responding induced by cocaine cues versus cocaine priming over the first 6 months. Psychopharmacology (Berl) 176, 101-108 (2004).

40. Grimm, J. W., Shaham, Y. \& Hope, B. T. Effect of cocaine and sucrose withdrawal period on extinction behavior, cue-induced reinstatement, and protein levels of the dopamine transporter and tyrosine hydroxylase in limbic and cortical areas in rats. Behav Pharmacol 13, 379-388 (2002)

41. Shalev, U., Grimm, J. W. \& Shaham, Y. Neurobiology of relapse to heroin and cocaine seeking: a review. Pharmacol Rev 54, 1-42 (2002).

42. Tornatzky, W. \& Miczek, K. A. Cocaine self-administration "binges": transition from behavioral and autonomic regulation toward homeostatic dysregulation in rats. Psychopharmacology (Berl) 148, 289-298 (2000).

43. Quadros, I. M. \& Miczek, K. A. Two modes of intense cocaine bingeing: increased persistence after social defeat stress and increased rate of intake due to extended access conditions in rats. Psychopharmacology (Berl) 206, 109-120 (2009).

44. Mutschler, N. H. \& Miczek, K. A. Withdrawal from i.v. cocaine "binges" in rats: ultrasonic distress calls and startle. Psychopharmacology (Berl) 135, 161-168 (1998).

45. Mutschler, N. H., Covington, H. E., 3rd \& Miczek, K. A. Repeated selfadministered cocaine "binges" in rats: effects on cocaine intake and withdrawal. Psychopharmacology (Berl) 154, 292-300 (2001).

46. Fowler, S. C., Covington, H. E., 3rd \& Miczek, K. A. Stereotyped and complex motor routines expressed during cocaine self-administration: results from a 24-h binge of unlimited cocaine access in rats. Psychopharmacology (Berl) 192, 465-478 (2007)

47. Covington, H. E., 3rd et al. Brief social defeat stress: long lasting effects on cocaine taking during a binge and zif268 mRNA expression in the amygdala and prefrontal cortex. Neuropsychopharmacology 30, 310-321 (2005).

48. Weiss, R. D., Griffin, M. L. \& Hufford, C. Severity of cocaine dependence as a predictor of relapse to cocaine use. Am J Psychiatry 149, 1595-1596 (1992).

49. Markou, A. et al. Animal models of drug craving. Psychopharmacology (Berl) 112, 163-182 (1993)

50. Mutschler, N. H. \& Miczek, K. A. Withdrawal from a self-administered or non contingent cocaine binge: differences in ultrasonic distress vocalizations in rats. Psychopharmacology (Berl) 136, 402-408 (1998).

51. O’Brien, C. P., Childress, A. R., Ehrman, R. \& Robbins, S. J. Conditioning factors in drug abuse: can they explain compulsion? J Psychopharmacol 12, 15-22 (1998).

52. Weisshaar, E. et al. The symptom of itch in medical history: highlights through the centuries. Int J Dermatol 48, 1385-1394 (2009).

53. Podlesnik, C. A., Jimenez-Gomez, C. \& Woods, J. H. A choice procedure to assess the aversive effects of drugs in rodents. J Exp Anal Behav 93, 203-223 (2010).

54. Holtz, N. A., Anker, J. J., Regier, P. S., Claxton, A. \& Carroll, M. E. Cocaine selfadministration punished by i.v. histamine in rat models of high and low drug abuse vulnerability: effects of saccharin preference, impulsivity, and sex. Physio Behav 122, 32-38 (2013).

55. Negus, S. S. Effects of punishment on choice between cocaine and food in rhesus monkeys. Psychopharmacology (Berl) 181, 244-252 (2005)

56. Woolverton, W. L., Freeman, K. B., Myerson, J. \& Green, L. Suppression of cocaine self-administration in monkeys: effects of delayed punishment. Psychopharmacology (Berl) 220 (2012).

57. Cummins, E. \& Leri, F. Unreinforced responding during limited access to heroin self-administration. Pharmacol Biochem Behav 90, 420-427 (2008).

58. Hollander, J. A. et al. Striatal microRNA controls cocaine intake through CREB signalling. Nature 466, 197-202 (2010).

59. Deroche-Gamonet, V., Belin, D. \& Piazza, P. V. Evidence for addiction-like behavior in the rat. Science 305, 1014-1017 (2004).

60. Gancarz, A. M., Kausch, M. A., Lloyd, D. R. \& Richards, J. B. Between-session progressive ratio performance in rats responding for cocaine and water reinforcers. Psychopharmacology (Berl) 222, 215-223 (2012).

61. Sakai, M. Constraints on decay of environmental sound memory in adult rats. Neuroreport 17, 1773-1777 (2006).

62. Briand, L. A., Flagel, S. B., Seeman, P. \& Robinson, T. E. Cocaine selfadministration produces a persistent increase in dopamine D2 High receptors. Eur Neuropsychopharmacol 18, 551-556 (2008)

63. Briand, L. A. et al. Persistent alterations in cognitive function and prefrontal dopamine D2 receptors following extended, but not limited, access to selfadministered cocaine. Neuropsychopharmacology 33, 2969-2980 (2008). 
64. Briand, L. A., Gross, J. P. \& Robinson, T. E. Impaired object recognition following prolonged withdrawal from extended-access cocaine self-administration. Neuroscience 155, 1-6 (2008).

65. George, O., Mandyam, C. D., Wee, S. \& Koob, G. F. Extended access to cocaine self-administration produces long-lasting prefrontal cortex-dependent working memory impairments. Neuropsychopharmacology 33, 2474-2482 (2008).

66. Pace-Schott, E. F. et al. Cocaine users differ from normals on cognitive tasks which show poorer performance during drug abstinence. Am J Drug Alcohol Abuse 34, 109-121 (2008).

67. Morgan, D., Brebner, K., Lynch, W. J. \& Roberts, D. C. Increases in the reinforcing efficacy of cocaine after particular histories of reinforcement. Behav Pharmacol 13, 389-396 (2002)

68. Barnea-Ygael, N., Yadid, G., Yaka, R., Ben-Shahar, O. \& Zangen, A. Cue-induced reinstatement of cocaine seeking in the rat "conflict model": effect of prolonged home-cage confinement. Psychopharmacology (Berl) 219, 875-883 (2012).

69. Nestler, E. J. Molecular basis of long-term plasticity underlying addiction. Nat Rev Neurosci 2, 119-128 (2001).

70. Hyman, S. E., Malenka, R. C. \& Nestler, E. J. Neural mechanisms of addiction: the role of reward-related learning and memory. Annu Rev Neurosci 29, 565-598 (2006).

71. Dietz, D. M., Dietz, K. C., Nestler, E. J. \& Russo, S. J. Molecular mechanisms of psychostimulant-induced structural plasticity. Pharmacopsychiatry 42 Suppl 1, S69-78 (2009).

72. Russo, S. J. et al. The addicted synapse: mechanisms of synaptic and structural plasticity in nucleus accumbens. Trends Neurosci 33, 267-276.

73. Weddington, W. W. et al. Changes in mood, craving and sleep during acute abstinence reported by male cocaine addicts. NIDA Res Monogr 105, 453-454 (1990).

74. De Los Cobos, J. P. et al. Drug-dependent inpatients reporting continuous absence of spontaneous drug craving for the main substance throughout detoxification treatment. Drug Alcohol Rev 30, 403-410 (2011).

75. Otaka, M. et al. Exposure to cocaine regulates inhibitory synaptic transmission in the nucleus accumbens. J Neurosci 33, 6753-6758 (2013).

76. Conrad, K. L. et al. Formation of accumbens GluR2-lacking AMPA receptors mediates incubation of cocaine craving. Nature 454, 118-121 (2008).

77. Scheyer, A. F., Wolf, M. E. \& Tseng, K. Y. A protein synthesis-dependent mechanism sustains calcium-permeable AMPA receptor transmission in nucleus accumbens synapses during withdrawal from cocaine self-administration. J Neurosci 34, 3095-3100 (2014).

78. McCutcheon, J. E., Wang, X., Tseng, K. Y., Wolf, M. E. \& Marinelli, M. Calciumpermeable AMPA receptors are present in nucleus accumbens synapses after prolonged withdrawal from cocaine self-administration but not experimenteradministered cocaine. J Neurosci 31, 5737-5743 (2011).

79. McCutcheon, J. E. et al. Group I mGluR activation reverses cocaine-induced accumulation of calcium-permeable AMPA receptors in nucleus accumbens synapses via a protein kinase C-dependent mechanism. J Neurosci 31, 14536-14541 (2011).
80. Jakkamsetti, V. et al. Experience-induced Arc/Arg3.1 primes CA1 pyramidal neurons for metabotropic glutamate receptor-dependent long-term synaptic depression. Neuron 80, 72-79 (2013).

81. Maze, I. et al. Essential role of the histone methyltransferase G9a in cocaineinduced plasticity. Science 327, 213-216 (2010).

82. LaPlant, Q. \& Nestler, E. J. CRACKing the histone code: cocaine's effects on chromatin structure and function. Horm Behav 59, 321-330 (2011).

83. Robison, A. J. \& Nestler, E. J. Transcriptional and epigenetic mechanisms of addiction. Nat Rev Neurosci 12, 623-637 (2011).

84. Chandra, R. et al. Optogenetic inhibition of D1R containing nucleus accumbens neurons alters cocaine-mediated regulation of Tiam1. Front Mol Neurosci 6, 13 (2013).

85. Gancarz-Kausch, A. M. et al. Transforming growth factor beta receptor 1 is increased following abstinence from cocaine self-administration, but not cocaine sensitization. PLoS One 8, e83834 (2013).

\section{Acknowledgments}

This work was supported by R01DA037257 awarded to D.M.D. and NIAAA

T-32-AA007583. We would like to thank Drs. Karen Dietz, Paul Meyer, and Fraser Sim for their insightful comments on this manuscript. The cocaine tested in these experiments was gifted by NIDA.

\section{Author contributions}

A.M.G.-K. and D.A. performed and collected all data for Figures 1-4. A.M.G.-K. analyzed and prepared all figures. A.M.G.-K. and D.M.D. wrote the main text of the manuscript. All the authors have read and approved the final version of the manuscript.

\section{Additional information}

Competing financial interests: The authors declare no competing financial interests.

How to cite this article: Gancarz-Kausch, A.M., Adank, D.N. \& Dietz, D.M. Prolonged withdrawal following cocaine self-administration increases resistance to punishment in a cocaine binge. Sci. Rep. 4, 6876; DOI:10.1038/srep06876 (2014).

his work is licensed under a Creative Commons Attribution-NonCommercialNoDerivs 4.0 International License. The images or other third party material in this article are included in the article's Creative Commons license, unless indicated otherwise in the credit line; if the material is not included under the Creative Commons license, users will need to obtain permission from the license holder in order to reproduce the material. To view a copy of this license, visit http:// creativecommons.org/licenses/by-nc-nd/4.0/ 